\title{
Role of caspase-10 in the death of acute leukemia cells
}

\author{
WENJIAN GUO, AISHU DONG, XIAHUI PAN, XIAOJI LIN, YING LIN, \\ MUQING HE, BAOLING ZHU, LIMING JIN and RONGXING YAO
}

\begin{abstract}
Department of Medicine, The Second Affiliated Hospital and Yuying Children's Hospital, Wenzhou Medical University, Wenzhou, Zhejiang 0577, P.R. China
\end{abstract}

Received May 5, 2015; Accepted June 10, 2016

DOI: $10.3892 / 01.2016 .4785$

\begin{abstract}
Autophagy can protect cells from stress, but can also induce cancer cell death. Caspase-10 is now considered to be a factor that is associated with autophagy in cancer. The present study therefore investigated whether caspase-10 affects autophagy in acute leukemia cells. The rates of survival vs. apoptosis in acute leukemia HL-60 and Jurkat cells treated with drugs were tested using cell viability assays and flow cytometry, and the levels of caspase- 3 and -10 were tested by western blotting. In HL-60 cells that were treated with chemotherapy drugs combined with a caspase-10 inhibitor, the rate of survival decreased significantly compared with HL-60 cells treated with chemotherapy drugs alone. In contrast, the rate of survival of Jurkat cells treated with chemotherapy drugs combined with the caspase-10 inhibitor increased significantly compared with Jurkat cells treated with chemotherapy drugs alone. The results of the flow cytometry and western blotting showed that the changes in the survival rate may be caused by a change in the amount of apoptosis occurring in the Jurkat cells treated with chemotherapy drugs combined with the caspase-10 inhibitor. However, in HL-60 cells undergoing this combination treatment, the change in the survival rate was not caused by a change in the rate of apoptosis. When HL-60 cells were treated with the chemotherapy drugs combined with the caspase-10 inhibitor and the autophagy inhibitor 3-methyl adenine, the survival rate increased, whereas the rate of apoptosis did not change. These results show that caspase-10 may be associated with autophagy in acute myeloid leukemia cells, but not in acute lymphatic leukemia cells.
\end{abstract}

\section{Introduction}

The term autophagy (literally 'self-eating') indicates a number of distinct cellular processes, which together share

Correspondence to: Professor Rongxing Yao, Department of Medicine, The Second Affiliated Hospital and Yuying Children's Hospital, Wenzhou Medical University, 109 College West Road, Wenzhou, Zhejiang 0577, P.R. China

E-mail: cainiao1981@163.com

Key words: caspase-10, autophagy, apoptosis, acute leukemia cells the outcome of the degradation of intracellular components by the lysosome, and are critical for maintaining normal cellular homeostasis $(1,2)$. The role of autophagy in regulating either cancer cell death or survival remains highly controversial. Due to the tumor suppressive and tumor promoting properties, at a first glance, autophagy may appear paradoxical. Indeed, the knockdown of genes involved in the autophagic process can either enhance or prevent cancer cell death (3). Acute leukemia (AL) is a malignant neoplastic hematological disorder, and the role of autophagy in AL is currently a hot topic. Since the 1990s, studies have highlighted the occurrence of autophagy in AL cells. Reviewing the ambiguous importance of autophagy in either promoting or suppressing AL cell growth and survival, Evangelisti et al (4) indicated that autophagy may represent a distinct mechanism of cell death, referred to as autophagic cell death (ACD), which also occurs in established tumors, including AL (5-8). In addition, autophagy can promote necroptosis, a non-apoptotic form of regulated cell death (9-10). According to these studies, ACD may be a means for treating this type of hematological malignancy and for enhancing the activity of current therapies. However, it is first necessary to establish the factors that control ACD.

There are several signal channels associated with autophagy, including mammalian target of rapamycin and Beclin1. The complex that is composed of Beclin1 and B cell lymphoma-2 (Bcl-2) is the major regulating factor in the Beclin1 channel (11-13). Beclin1 and Bcl-2 have antagonistic roles; Beclin1 can promote autophagy, but $\mathrm{Bcl}-2$ can inhibit autophagy. A recent study indicated that ACD was controlled by caspase-10 through regulating the balance of Beclin1 and Bcl-2 in multiple myeloma (14). Caspase-10 belongs to the caspase family, and its paralogue, caspase8, initiates a type of programmed cell death known as apoptosis (15). However, Lamy et al (14) showed that caspase-10 is an important factor in maintaining a balanced level of autophagy; when caspase-10 was inhibited, ACD of myeloma cell was caused by the excessive activation of Beclin1.

The study by Liu et al (16) mentioned that common chemotherapy drugs, including vincristine (VCR), arsenic trioxide and adriamycin (ADM), may cause the appearance of autophagosomes in AL cells by causing the increased expression of high mobility group box-1 protein. In addition, a literature review of autophagy in leukemia cells revealed that no other study had reported that caspase-10 was associated with autophagy in AL cells $(17,18)$. Therefore, the present study 
considered whether ACD could be controlled by caspase-10 in $\mathrm{AL}$, as in multiple myeloma. In the present study, the rate of survival of AL cells treated with chemotherapy drugs combined with a caspase-10 inhibitor was compared with AL cells treated with chemotherapy drugs alone. Methods such as flow cytometry and western blotting were used to investigate whether caspase-10 is associated with apoptosis or autophagy in this context.

\section{Materials and methods}

Reagents. The antibodies to caspase-3 were obtained from Cell Signaling Technology (Danvers, MA, USA). The caspase-10 antibody was obtained from Abcam (Shanghai, China). Cytosine arabinoside was purchased from Sigma-Aldrich (St. Louis, MO, USA). Anti-caspase 3 antibody (monoclonal, rabbit; 1:1,000 dilution; catalog no. 9662) was purchased from Cell Signaling Technology, anti-caspase-10 antibody (monoclonal, rabbit; 1:1,000 dilution; catalog no. ab177475) was purchased from Abcam and anti-GAPDH antibody (control; polyclonal, rabbit; 1:5,000 dilution; catalog no. AP0063) was purchased from Bioworld Technology Inc. (St. Louis Park, MN, USA). Goat anti-rabbit immunoglobulin G-horse radish peroxidase conjugated secondary antibody (1:500-1:5,000 dilution; catalog no. BS13278) was purchased from Bioworld Technology Inc. VCR, arsenic trioxide, ADM, the caspase-10 inhibitor (z-aevd-fmk) and 3-methyladenine (3-MA) were purchased from Sigma-Aldrich.

Cell culture. The human leukemia cell lines, HL-60 (derived from an acute myeloid leukemia) and Jurkat (derived from an acute lymphoid leukemia), were obtained from the American Type Culture Collection (Manassas, VA, USA) and cultured in Iscove's modified Dulbecco's medium or RPMI-1640 medium (Invitrogen; Thermo Fisher Scientific, Inc., Waltham, MA, USA), respectively, with $10 \%$ heat-inactivated fetal bovine serum, $2 \mathrm{mM}$ glutamine and an antibiotic-antimycotic mix (containing 10,000 U/ml penicillin, 10,000 $\mu \mathrm{g} / \mathrm{ml}$ streptomycin and $25 \mu \mathrm{g} / \mathrm{ml}$ amphotericin B), in a humidified incubator with $5 \% \mathrm{CO}_{2}$.

Cell viability assay. Cells were plated at a density of $5 \times 10^{4}$ cells/well in 96-well plates in $100 \mu \mathrm{l}$ medium. The chemotherapy drugs used for the treatment were VCR $(1 \mu \mathrm{g} / \mathrm{ml})$, ADM $(1 \mu \mathrm{g} / \mathrm{ml})$, cytosine arabinoside (Ara-c; $0.2 \mu \mathrm{M})$ and arsenic trioxide $\left(\mathrm{AS}_{2} \mathrm{O}_{3} ; 2.5 \mu \mathrm{M}\right)$. Following treatment for $24 \mathrm{~h}$, cell viability was evaluated using Cell Counting Kit-8 (Dojindo Molecular Technologies, Inc., Kumamoto, Japan), according to the manufacturer's instructions. In parallel, an analysis of cell viability by trypan blue (Sigma-Aldrich; catalog no. 302643) MSDS exclusion assay was performed according the manufacturer's instructions, which yielded similar results (data not shown). Assessment of apoptosis by flow cytometric analysis using Annexin V-phycoerythrin (PE; Sigma-Aldrich) was used in conjunction with a vital dye, 7-amino actinomycin D (7-AAD), to distinguish apoptotic (Annexin V-PE positive, 7-AAD negative) from necrotic (Annexin V-PE positive, 7-AAD positive) cells. After treatment, cells were trypsinized, collected and resuspended in $40 \mu \mathrm{l}$ binding buffer with $2 \mu \mathrm{l}$ Annexin V-PE. Cells were incubated for $15 \mathrm{~min}$ in the dark at room temperature. Subsequent to incubation, $160 \mu 1$ binding buffer and $2 \mu 1$ 7-AAD were added. Cells were then incubated for $5 \mathrm{~min}$ and additional $200 \mu \mathrm{l}$ binding buffer was added. Prior to analysis, the cells were filtered through a cell strainer cap fitted to a polystyrene, round bottomed, flow cytometric tube. Data were collected and analyzed by a FACS Calibur flow cytometer with CellQuest Pro software version 5.1 (BD Biosciences, Franklin Lakes, NJ, USA), with a total of 10,000 events per sample. Fluorescence was measured and the percentage of viable, early apoptotic, late apoptotic and necrotic cells was determined.

Western blot analysis. Cells were lysed in $20 \mathrm{mM}$ Tris (pH 7.5), $150 \mathrm{mM} \mathrm{NaCl}, 1 \mathrm{mM}$ ethylenediaminetetraacetic acid and $1 \%$ Tergitol-type NP-40 supplemented with a protease inhibitor (Complete Mini EDTA-free; Roche Diagnostics, Indianapolis, IN, USA) and phosphatase inhibitor mixture II (Sigma-Aldrich). In all, $30 \mathrm{mg}$ of protein per lane was run on a denaturing $10 \%$ sodium dodecyl sulfate-polyacrylamide gel and subsequently transferred to polyvinylidene fluoride membranes via semidry transfer. After blocking the membrane at room temperature for $3 \mathrm{~h}$, the membrane was incubated overnight at $4^{\circ} \mathrm{C}$ with anti-caspase- 3 and -10 antibodies. After incubation with peroxidase-conjugated secondary antibodies for $1 \mathrm{~h}$ at $25^{\circ} \mathrm{C}$, the signals were visualized using enhanced chemiluminescence (Pierce; Thermo Fisher Scientific, Inc.).

Statistical analysis. Results were expressed as mean \pm standard deviation $(\mu \pm \mathrm{SD})$. The significance of differences was calculated by one-way analysis of variance, and the threshold for indicating a significant difference was defined as $\mathrm{P}<0.05$. SPSS 20.0 (IBM SPSS, Armonk, NY, USA) was used for all statistical analyses.

\section{Results}

Survival rate of HL-60 and Jurkat cells treated with chemotherapy drugs or chemotherapy drugs combined with a caspase-10 inhibitor. The survival rates of HL-60 cells treated with the following chemotherapy drugs alone were: $\mathrm{AS}_{2} \mathrm{O}_{3}, 76.92 \pm 8.44$; ADM, 67.92 \pm 4.39 ; VCR, 65.86 \pm 20.25 ; and Ara-c, $83.81 \pm 15.11$. The survival rate of HL-60 cells treated with chemotherapy drugs combined with a caspase-10 inhibitor (z-aevd-fmk) was lower compared with the group treated with only chemotherapy drugs. The survival rates of HL-60 cells treated with chemotherapy drugs combined with the caspase-10 inhibitor were: $\mathrm{AS}_{2} \mathrm{O}_{3}, 67.83 \pm 4.81$; ADM,

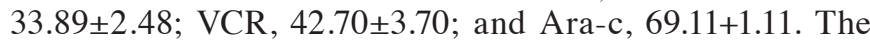
differences were significant. The survival rate of the HL-60 cells was also significantly decreased compared with the control when they were treated with the caspase-10 inhibitor alone $(\mathrm{P}=0.023$; Table I; Fig. 1A). The memebers of the caspase family are known to be important priming factors for apoptosis. However, the change in the survival rate of HL-60 cells appears to suggest that caspase-10 may not be associated with apoptosis in HL-60 cells.

The survival rates of Jurkat cells treated with only the chemotherapy drugs were: $\mathrm{AS}_{2} \mathrm{O}_{3}, 64.65 \pm 11.16$; $\mathrm{ADM}$,

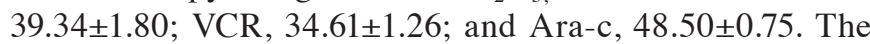
survival rate of Jurkat cells treated with the chemotherapy 
Table I. Survival and apoptotic rates of HL-60 and Jurkat cells treated with chemotherapy drugs or chemotherapy drug combined with z-aevd-fmk for $24 \mathrm{~h}$.

\begin{tabular}{lcrrr}
\hline & \multicolumn{2}{c}{ HL-60 cell } & & Jurkat cell \\
\cline { 2 - 5 } Treatment & Survival (\%) & Apoptosis (\%) & Survival (\%) & Apoptosis (\%) \\
\cline { 2 - 5 } Control & $102.55 \pm 9.46^{\mathrm{a}}$ & $0.51 \pm 0.11^{\mathrm{b}}$ & $100.62 \pm 8.73^{\mathrm{a}}$ & $0.62 \pm 0.12^{\mathrm{a}}$ \\
$\mathrm{AS}_{2} \mathrm{O}_{3}$ & $76.92 \pm 8.44^{\mathrm{a}}$ & $4.91 \pm 1.50^{\mathrm{b}}$ & $64.65 \pm 11.16^{\mathrm{a}}$ & $5.11 \pm 2.90^{\mathrm{a}}$ \\
$\mathrm{ADM}$ & $67.92 \pm 4.39^{\mathrm{a}}$ & $10.02 \pm 4.20^{\mathrm{b}}$ & $39.34 \pm 1.80^{\mathrm{a}}$ & $35.40 \pm 7.80^{\mathrm{a}}$ \\
$\mathrm{VCR}$ & $65.86 \pm 20.25^{\mathrm{a}}$ & $12.63 \pm 5.90^{\mathrm{b}}$ & $34.61 \pm 1.26^{\mathrm{a}}$ & $45.42 \pm 9.80^{\mathrm{a}}$ \\
$\mathrm{Ara}-\mathrm{c}$ & $83.81 \pm 15.11^{\mathrm{a}}$ & $2.12 \pm 1.20^{\mathrm{b}}$ & $48.50 \pm 0.75^{\mathrm{a}}$ & $20.20 \pm 3.20^{\mathrm{a}}$ \\
$\mathrm{Z}+\mathrm{blank}$ & $68.87 \pm 4.31^{\mathrm{a}}$ & $0.50 \pm 0.30^{\mathrm{b}}$ & $83.77 \pm 3.87^{\mathrm{a}}$ & $0.53 \pm 0.10^{\mathrm{b}}$ \\
$\mathrm{Z}+\mathrm{AS} \mathrm{O}_{3}$ & $67.83 \pm 4.81^{\mathrm{a}}$ & $3.61 \pm 1.80^{\mathrm{b}}$ & $79.27 \pm 1.83^{\mathrm{a}}$ & $1.10 \pm 0.90^{\mathrm{a}}$ \\
$\mathrm{Z}+\mathrm{ADM}$ & $33.89 \pm 2.48^{\mathrm{a}}$ & $9.01 \pm 3.40^{\mathrm{b}}$ & $44.01 \pm 2.85^{\mathrm{a}}$ & $12.21 \pm 5.60^{\mathrm{a}}$ \\
$\mathrm{Z}+\mathrm{VCR}$ & $42.70 \pm 3.70^{\mathrm{a}}$ & $10.50 \pm 5.40^{\mathrm{b}}$ & $57.23 \pm 0.49^{\mathrm{a}}$ & $14.30 \pm 5.40^{\mathrm{a}}$ \\
$\mathrm{Z}+$ Ara-c & $69.11 \pm 1.11^{\mathrm{a}}$ & $3.62 \pm 1.10^{\mathrm{b}}$ & $6.72 \pm 2.10^{\mathrm{a}}$ \\
\hline
\end{tabular}

$\mathrm{AS}_{2} \mathrm{O}_{3}$, arsenic trioxide $(2.5 \mu \mathrm{M}) ; \mathrm{ADM}$, adriamycin $(1 \mu \mathrm{g} / \mathrm{ml})$; VCR, vincristine $(1 \mu \mathrm{g} / \mathrm{ml})$; Ara-c, cytosine arabinoside $(0.2 \mu \mathrm{M}) ; \mathrm{Z}, \mathrm{caspase}-10$ inhibitor (z-aevd-fmk). ${ }^{a} \mathrm{P}<0.05$, ${ }^{\mathrm{b}} \mathrm{P}>0.05$, for the group treated with chemotherapy drugs only compared with the group treated with chemotherapy drugs combined with z-aevd-fmk.

drugs combined with the caspase-10 inhibitor was increased compared with the group treated with only the chemotherapy drugs. The survival rates of Jurkat cells treated with the chemotherapy drugs combined with the caspase-10 inhibitor

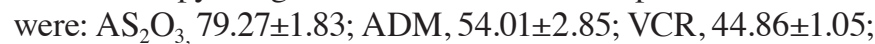
Ara-c, 57.23 \pm 0.49 . The differences were significant. However, the survival rate of Jurkat cells also significantly decreased compared with the control when it was treated with only the caspase-10 inhibitor ( $\mathrm{P}=0.019$; Table I; Fig. 1B). The change in the survival rate of Jurkat cells treated with chemotherapy drugs combined with caspase-10 inhibitor was different from HL-60 cells, and the result showed that caspase-10 was associated with the apoptosis in Jurkat cells. However, the change in the survival rate of Jurkat cells treated with only the caspase-10 inhibitor was similar to the survival rate of HL-60 cells.

Rate of apoptosis in HL-60 and Jurkat cells treated with chemotherapy drugs or chemotherapy drugs combined with a caspase-10 inhibitor. According to the change in survival rate of HL-60 treated by chemotherapy drugs combined with caspase-10 inhibitor, the present study examined whether the result was associated with the change in the rate of apoptosis. Thus, the rate of apoptosis in HL-60 cell treated in various ways was tested. The rates of apoptosis in HL-60 cells treated with chemotherapy drugs for $24 \mathrm{~h}$ were: $\mathrm{AS}_{2} \mathrm{O}_{3}, 4.9 \pm 1.5$;

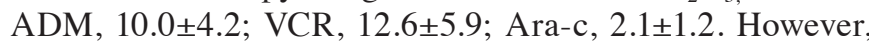
there was no significant difference in the rate of apoptosis between the group treated with chemotherapy drugs combined with caspase-10 inhibitor and the group treated with only the chemotherapy drugs. In addition, there was no significant difference in the rate of apoptosis in HL-60 cells treated with only the caspase-10 inhibitor compared with the control $(\mathrm{P}=0.231$; Table I; Fig. 2A). This result showed that the change in survival rate could not be explained by apoptosis.

The change in the rate of apoptosis was different between the Jurkat cells and the HL-60 cells. The rates of apoptosis in Jurkat cells treated with the chemotherapy drugs for $24 \mathrm{~h}$

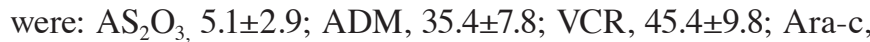
$20.2 \pm 3.2$. The rate of apoptosis decreased significantly compared with the control in the Jurkat cells treated with chemotherapy drugs combined with caspase-10 inhibitor ( $\mathrm{P}=0.021$; Table I, Fig. 2B). However, there was no significant difference in the rate of apoptosis in the Jurkat cells treated with only the caspase-10 inhibitor ( $\mathrm{P}=0.114$; Table I; Fig. 2B). The change in the rate of apoptosis was also different between the Jurkat cells treated by chemotherapy drugs combined with caspase-10 inhibitor and only the caspase-10 inhibitor.

Levels of caspase-3 and -10 in HL-60 and Jurkat cells treated with either chemotherapy drugs or chemotherapy drugs combined with a caspase-10 inhibitor. The expression of caspase- 3 and -10 decreased in HL-60 cells when the cells were treated with chemotherapy drugs compared with the control group, and the cleaved forms of caspase- 3 and -10 increased in the ADM and VCR groups. When the cells were treated with chemotherapy drugs combined with the caspase-10 inhibitor, the expression of caspase-3 and -10 were similar to the group treated with the chemotherapy drugs alone (Fig. 3A). This result also showed the change in survival rate could not explained by apoptosis in HL-60 cells.

The expression of caspase- 3 and -10 decreased in Jurkat cells when the cells were treated with chemotherapy drugs compared with the blank group, and the cleaved forms of caspase-3 and -10 increased in the ADM, VCR and Ara-c treated groups. When the cells were treated with the chemotherapy drugs in combination with the caspase-10 inhibitor, the expression of caspase-3 and -10 increased, and the cleaved forms of caspase -3 and -10 decreased more compared with the group treated with chemotherapy drugs alone (Fig. 3B). This result also showed the change in survival rate could be explained by apoptosis in Jurkat cells. 
A

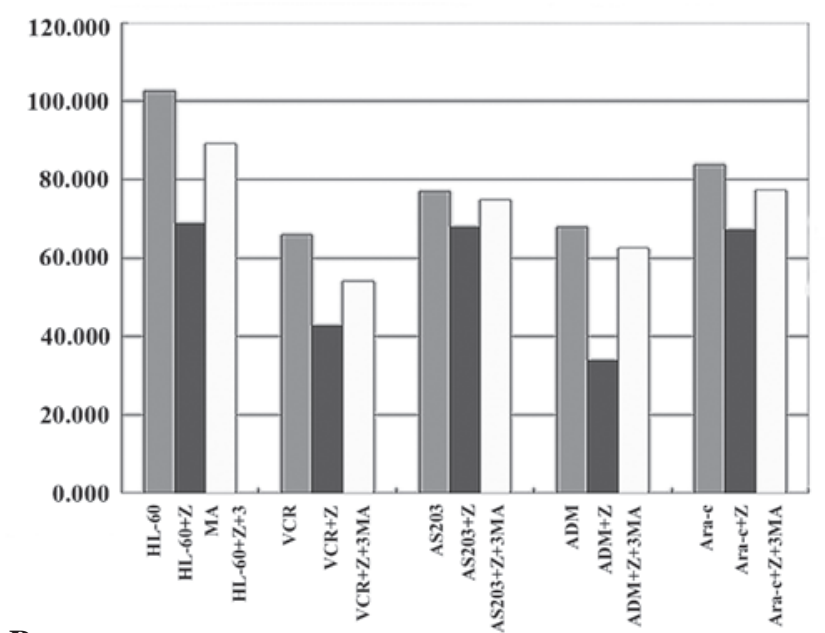

B

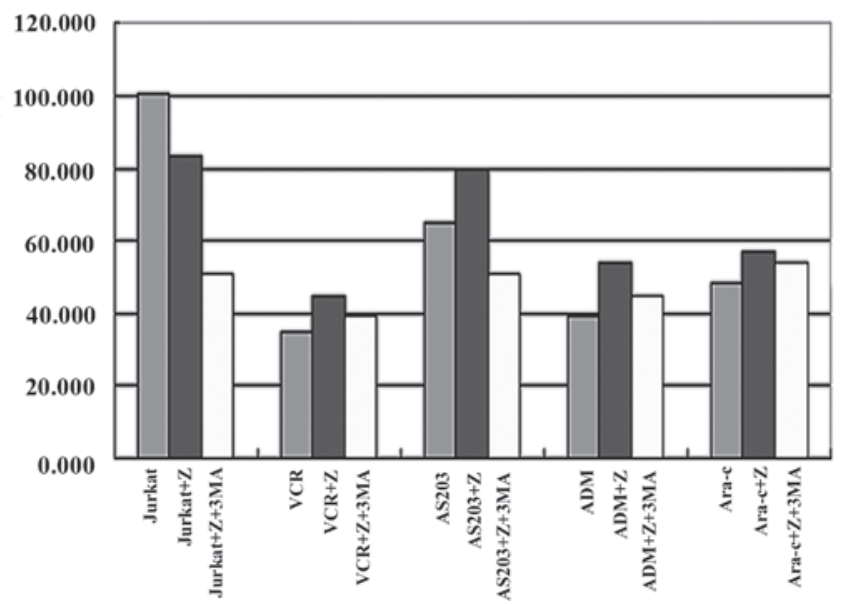

Figure 1. Survival rates in HL-60 and Jurkat cells when treated with a caspase-10 inhibitor (z-aevd-fmk), a caspase-10 inhibitor (z-aevd-fmk) with 3-MA, a chemotherapy drug, a chemotherapy drug combined with a caspase-10 inhibitor (z-aevd-fmk) and a chemotherapy drug combined with a caspase-10 inhibitor (z-aevd-fmk) and 3-MA: (A) Survival rate in HL-60 cells when treated with a caspase-10 inhibitor ( $\mathrm{z}$-aevd-fmk), a caspase-10 inhibitor (z-aevd-fmk) with 3-MA, a chemotherapy drug, a chemotherapy drug combined with a caspase-10 inhibitor (z-aevd-fmk) and a chemotherapy drug combined with a caspase-10 inhibitor (z-aevd-fmk) and 3-MA; (B) Survival rate in Jurkat cells when treated with a caspase-10 inhibitor (z-aevd-fmk), a caspase-10 inhibitor (z-aevd-fmk) with 3-MA, a chemotherapy drug, a chemotherapy drug combined with a caspase-10 inhibitor (z-aevd-fmk) and a chemotherapy drug combined with a caspase-10 inhibitor (z-aevd-fmk) and 3-MA. Z, caspase-10 inhibitor (z-aevd-fmk); 3-MA, 3-methyladenine; VCR, vincristine; $\mathrm{AS}_{2} \mathrm{O}_{3}$, arsenic trioxide; $\mathrm{ADM}$, adriamycin; Ara-c, cytosine arabinoside.

Survival rate of HL-60 and Jurkat cells treated with chemotherapy drugs combined with a caspase-10 inhibitor and 3-MA. As the change in rate of apoptosis was not significant in HL-60 cells treated in various ways, the present study considered that the survival rate may be associated with ACD. Thus, the autophagy inhibitor, 3-MA, was used. The survival rates of HL-60 cells treated with chemotherapy drugs combined with the caspase-10 inhibitor and 3-MA were: $\mathrm{AS}_{2} \mathrm{O}_{3}, 74.82 \pm 1.02$; ADM, 62.37 \pm 1.30 ; VCR, 54.09 \pm 2.03 ; and Ara-c, 20.2 \pm 3.2 . The results showed that the survival rate was increased compared with the group treated with chemotherapy drugs combined with the caspase-10 inhibitor. The survival rate also increased
A
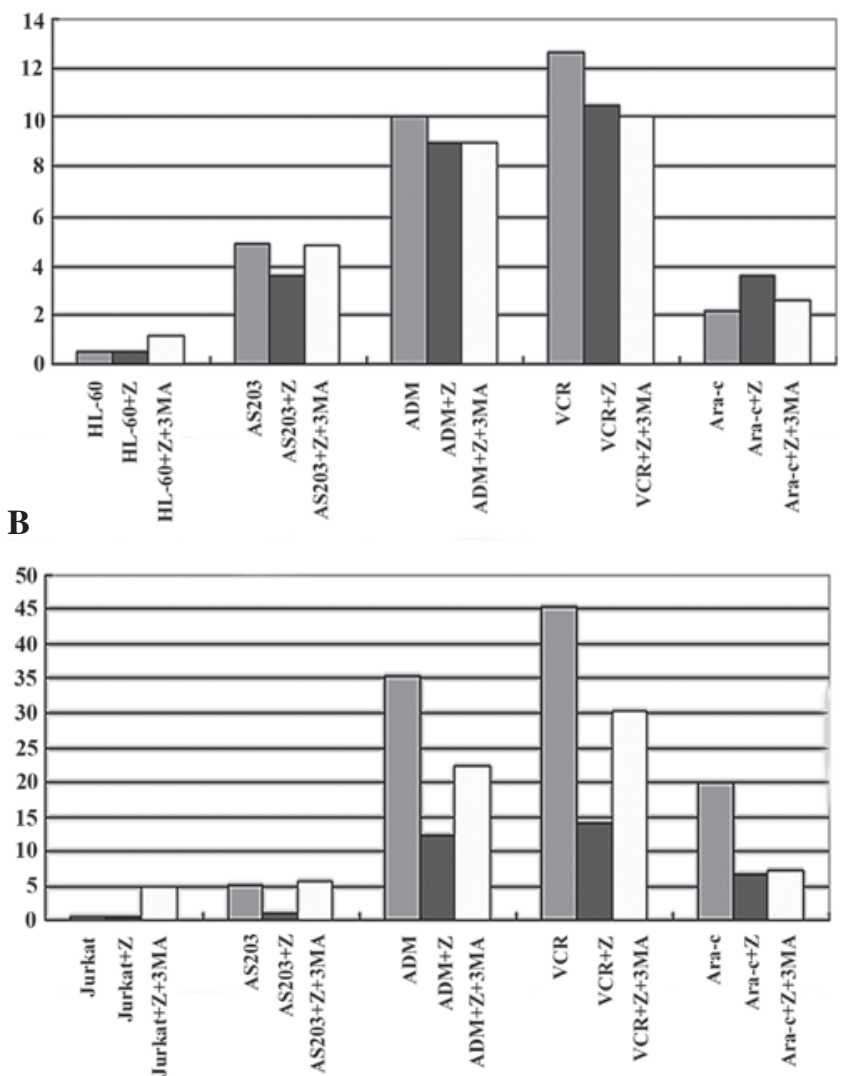

Figure 2. Rate of apoptosis in HL-60 and Jurkat cells when treated with a caspase-10 inhibitor (z-aevd-fmk), a caspase-10 inhibitor (z-aevd-fmk) with 3-MA, a chemotherapy drug, a chemotherapy drug combined with a caspase-10 inhibitor (z-aevd-fmk) and a chemotherapy drug combined with a caspase-10 inhibitor (z-aevd-fmk) and 3-MA: (A) Rate of apoptosis in HL-60 cells when treated with a caspase-10 inhibitor (z-aevd-fmk), a caspase-10 inhibitor (z-aevd-fmk) with 3-MA, a chemotherapy drug, a chemotherapy drug combined with a caspase-10 inhibitor (z-aevd-fmk) and a chemotherapy drug combined with a caspase-10 inhibitor (z-aevd-fmk) and 3-MA; (B) Rate of apoptosis in Jurkat cells when treated with a caspase-10 inhibitor (z-aevd-fmk), a caspase-10 inhibitor (z-aevd-fmk) with 3-MA, a chemotherapy drug, a chemotherapy drug combined with a caspase-10 inhibitor (z-aevd-fmk) and a chemotherapy drug combined with a caspase-10 inhibitor (z-aevd-fmk) and 3-MA. Z, caspase-10 inhibitor (z-aevd-fmk); 3-MA, 3-methyladenine; $\mathrm{AS}_{2} \mathrm{O}_{3}$, arsenic trioxide; $\mathrm{ADM}$, adriamycin; VCR, vincristine; Ara-c, cytosine arabinoside.

in HL-60 cells treated with the caspase-10 inhibitor combined with 3-MA, compared with the group treated with caspase-10 inhibitor alone ( $\mathrm{P}=0.01$; Table II; Fig. 1A). The results showed that the change in survival rate was associated with ACD.

The same test was also performed on the Jurkat cells group. The survival rates of the Jurkat cells treated with chemotherapy drugs combined with the caspase-10 inhibitor and 3-MA were: $\mathrm{AS}_{2} \mathrm{O}_{3}, 50.39 \pm 4.80$; $\mathrm{ADM}, 44.99 \pm 3.67$; VCR, $39.38 \pm 4.01$; and Ara-c, 54.32 \pm 2.34 . The results showed that the survival rate decreased compared with the group treated with chemotherapy drugs combined with the caspase-10 inhibitor. The survival rate also decreased in the Jurkat cells treated with the caspase-10 inhibitor combined with 3-MA compared with the group treated with the caspase-10 inhibitor alone $(\mathrm{P}=0.013$; Table II; Fig. 1B). The result showed that treatment with 3-MA could result in the decreased survival rate of Jurkat cells, which was different from the result found in HL-60 cells. 
Table II. Survival and apoptotic rates of HL-60 and Jurkat cells treated with chemotherapy drugs combined with z-aevd-fmk and 3-MA for $24 \mathrm{~h}$

\begin{tabular}{|c|c|c|c|c|}
\hline \multirow[b]{2}{*}{ Treatment } & \multicolumn{2}{|c|}{ HL-60 cell } & \multicolumn{2}{|c|}{ Jurkat cell } \\
\hline & Survival (\%) & Apoptosis (\%) & Survival (\%) & Apoptosis (\%) \\
\hline Control & $102.55 \pm 9.46^{\mathrm{a}}$ & $0.51 \pm 0.11^{\mathrm{b}}$ & $100.62 \pm 8.73^{\mathrm{a}}$ & $0.62 \pm 0.12^{\mathrm{a}}$ \\
\hline Z+control & $68.87 \pm 4.31^{\mathrm{a}}$ & $0.50 \pm 0.30^{b}$ & $83.77 \pm 3.87^{\mathrm{a}}$ & $0.53 \pm 0.10^{\mathrm{b}}$ \\
\hline 3-MA+Z+blank & $89.12 \pm 3.25^{\mathrm{a}}$ & $1.21 \pm 0.20^{\mathrm{b}}$ & $50.61 \pm 4.78$ & $5.03 \pm 0.30^{\mathrm{a}}$ \\
\hline $3-\mathrm{MA}+\mathrm{Z}+\mathrm{AS}_{2} \mathrm{O}_{3}$ & $74.82 \pm 1.02^{\mathrm{a}}$ & $4.83 \pm 2.10^{\mathrm{b}}$ & $50.39 \pm 4.80$ & $5.62 \pm 1.10^{\mathrm{a}}$ \\
\hline 3-MA+Z+ADM & $62.37 \pm 1.30^{\mathrm{a}}$ & $9.00 \pm 2.30^{\mathrm{b}}$ & $44.99 \pm 3.67$ & $22.20 \pm 5.80^{\mathrm{a}}$ \\
\hline 3-MA+Z+VCR & $54.09 \pm 2.03^{\mathrm{a}}$ & $10.01 \pm 3.20^{\mathrm{b}}$ & $39.38 \pm 4.01$ & $30.20 \pm 2.30^{\mathrm{a}}$ \\
\hline 3-MA+Z+Ara-c & $77.17 \pm 5.65^{\mathrm{a}}$ & $2.61 \pm 0.90^{\mathrm{b}}$ & $54.32 \pm 2.34$ & $7.20 \pm 1.10^{\mathrm{a}}$ \\
\hline $\mathrm{Z}+\mathrm{AS}_{2} \mathrm{O}_{3}$ & $67.83 \pm 4.81^{\mathrm{a}}$ & $3.61 \pm 1.80^{\mathrm{b}}$ & $79.27 \pm 1.83^{\mathrm{a}}$ & $1.10 \pm 0.90^{\mathrm{a}}$ \\
\hline $\mathrm{Z}+\mathrm{ADM}$ & $33.89 \pm 2.48^{\mathrm{a}}$ & $9.01 \pm 3.40^{\mathrm{b}}$ & $54.01 \pm 2.85^{\mathrm{a}}$ & $12.21 \pm 5.60^{\mathrm{a}}$ \\
\hline $\mathrm{Z}+\mathrm{VCR}$ & $42.70 \pm 3.70^{\mathrm{a}}$ & $10.50 \pm 5.40^{\mathrm{b}}$ & $44.86 \pm 1.05^{\mathrm{a}}$ & $14.30 \pm 5.40^{\mathrm{a}}$ \\
\hline Z+Ara-c & $69.11 \pm 1.11^{\mathrm{a}}$ & $3.62 \pm 1.10^{\mathrm{b}}$ & $57.23 \pm 0.49^{\mathrm{a}}$ & $6.72 \pm 2.10^{\mathrm{a}}$ \\
\hline
\end{tabular}

Z, caspase-10 inhibitor (z-aevd-fmk); 3-MA, 3-methyladenine; $\mathrm{AS}_{2} \mathrm{O}_{3}$, arsenic trioxide $(2.5 \mu \mathrm{M})$; ADM, adriamycin (1 $\left.\mu \mathrm{g} / \mathrm{ml}\right)$; VCR, vincristine $(1 \mu \mathrm{g} / \mathrm{ml})$; Ara-c, cytosine arabinoside $(0.2 \mu \mathrm{M})$. ${ }^{\mathrm{a}} \mathrm{P}<0.05$, ${ }^{\mathrm{b}} \mathrm{P}>0.05$, for the group treated with the chemotherapy drugs combined with $\mathrm{z}$-aevd-fmk compared with the group treated with the chemotherapy drugs combined with z-aevd-fmk and 3-MA.
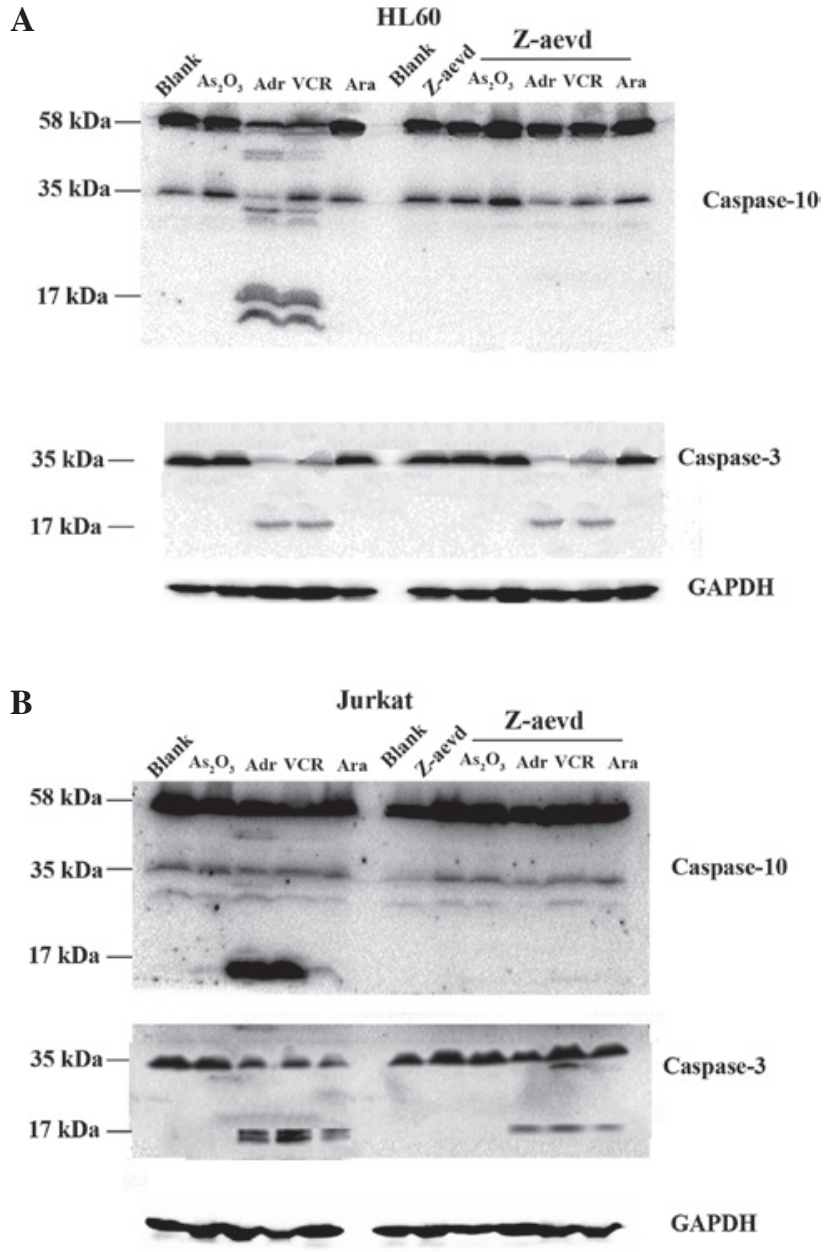

Figure 3. Levels of caspase-3 and 10 in HL-60 and Jurkat cells treated with chemotherapy drugs or chemotherapy drugs combined with caspase-10 inhibitor: Levels of caspase-3 and 10 in (A) HL-60 and (B) Jurkat cells treated with chemotherapy drugs or chemotherapy drugs combined with caspase-10 inhibitor.
Rate of apoptosis in HL-60 and Jurkat cells treated with chemotherapy drugs combined with a caspase-10 inhibitor and 3-MA. The rates of apoptosis in HL-60 cells treated with chemotherapy drugs combined with the caspase-10 inhibitor and 3-MA for $24 \mathrm{~h}$ were: $\mathrm{AS}_{2} \mathrm{O}_{3}, 4.8 \pm 2.1$; ADM, 9.0 2.3; VCR, 10.0 \pm 3.2 ; and Ara-c, 2.6 \pm 0.9 . There was no significant difference between the group treated with chemotherapy drugs combined with the caspase-10 inhibitor and 3-MA and the group treated with the chemotherapy drugs combined with the caspase-10 inhibitor. The rate of apoptosis in the group treated with 3-MA or caspase-10 inhibitor alone was extremely low ( $\mathrm{P}=0.095$; Table II; Fig. 2A), and there was no significant difference between the group treated with 3-MA and the group treated with the caspase-10 inhibitor $(\mathrm{P}=0.21$; Table II; Fig. 2A).

The rates of apoptosis in Jurkat cells treated with chemotherapy drugs combined with the caspase-10 inhibitor and 3-MA for $24 \mathrm{~h}$ were: $\mathrm{AS}_{2} \mathrm{O}_{3}, 5.6 \pm 1.1$; ADM, 22.2 \pm 5.8 ; VCR, $30.2 \pm 2.3$; and Ara-c, $6.7 \pm 1.1$. The rate of apoptosis increased significantly in the group treated with chemotherapy drugs combined with caspase-10 inhibitor and 3-MA compared with the group treated with the chemotherapy drugs combined with the caspase-10 inhibitor ( $\mathrm{P}=0.21$; Table II; Fig. $2 \mathrm{~B})$. The rate of apoptosis in the group treated only with 3-MA was increased compared with the rate of apoptosis in the group treated with only the caspase-10 inhibitor ( $\mathrm{P}=0.011$; Table II; Fig. 2B).

\section{Discussion}

Autophagy is critical for maintaining normal cellular homeostasis; basal levels of autophagy are required to maintain cellular fitness and the quality control of essential cellular components, by removing unfolded, excessive or aged proteins, as well as damaged or superfluous organelles (2,19-21). Cancer may be affected by defects in apoptosis, 
but the association between autophagy and cancer is complex. Whether autophagy is a promoter or killer of cancer cells remains a subject of discussion (22). Certain studies have indicated that autophagy could protect cancer cells when they are treated with chemotherapy $(23,24)$, and others suggest that autophagy may be associated with chemotherapy or radiation therapy resistance $(25,26)$. However, other studies have mentioned that the excessive activation of autophagy could result in the ACD of cancer cells (27), or contribute to ACD through unchecked degradative processes (7-9). From reviewing the literature, the authors of the present study have concluded autophagy may be a promoter or killer of cancer cells depending on the context. Thus, discovering the factors that regulate autophagy is key to manipulating autophagy for cancer therapy.

Lamy et al found an association between capase10 and autophagy in myeloma cells (14). Therefore, it may be hypothesized that caspase-10 is also important in autophagy in AL cells. In the present study, the survival rate of HL-60 cells decreased and the survival rate of Jurkat cells increased after the cells were treated with chemotherapy drugs combined with a caspase-10 inhibitor. However, the survival rate of the HL-60 and Jurkat cells decreased after the cells were treated with only the caspase-10 inhibitor. Therefore, tests were performed on the rate of apoptosis and the expression level of caspase- 3 to attempt to explain the change in the survival rate. These tests showed differences between the HL-60 and the Jurkat cells. The rate of apoptosis in the HL-60 cells did not change after the cells were treated with chemotherapy drugs combined with the caspase-10 inhibitor compared with the group treated with chemotherapy drugs alone. Caspase-3 analysis also showed that apoptosis was not activated after the cells were treated with chemotherapy drugs combined with the caspase-10 inhibitor. The results also indicated that the caspase-10 inhibitor did not activate apoptosis by itself. So the decreasing survival rate could not be explained by apoptosis in HL-60 cells. However, the change in the rate of apoptosis and the expression levels of caspase-3 in Jurkat cells showed that apoptosis was inhibited after the cells were treated with chemotherapy drugs combined with the caspase-10 inhibitor. According to these results, the increasing survival rate in Jurkat cells could be potentially caused by the inhibition apoptosis. However, the decreased Jurkat cell survival rate following treatment with only the caspase-10 inhibitor remains unexplained, since the caspase-10 inhibitor did not activate apoptosis by itself in Jurkat cells.

These results indicated that another type of cell death may be occurring in the HL-60 cells and in the Jurkat cells that were treated with only the caspase-10 inhibitor. Autophagy has been classified as a form of programmed cell death, termed ACD. This term describes a form of caspase-independent necrosis-like cell death associated with the accumulation of autophagosomes (27). Thus, the change in the survival rate may potentially be caused by ACD. 3-MA, which can inhibit autophagy, was added to the set of HL- 60 cells treated with the chemotherapy drugs combined with the caspase-10 inhibitor, or treated with only the caspase-10 inhibitor. The survival rate increased when 3-MA was added compared with the group treated with chemotherapy drugs combined with the caspase-10 inhibitor, or treated with the caspase-10 inhibitor only, and the rate of apoptosis did not decrease. The results also indicated that the rate of apoptosis was extremely low when the HL-60 cells were treated with 3-MA alone. Thus, caspase-10 could be associated with the basal level of autophagy in HL-60 cells, and ACD may increase in HL-60 cells when caspase-10 is inhibited. However, the survival rate remained decreased in the Jurkat cells when treated with the caspase-10 inhibitor in combination with 3-MA, as an increased rate of apoptosis was indicated compared with the rate of apoptosis in HL-60 cells. Therefore, the change in the survival rate in the Jurkat cells that had been treated with the caspase-10 inhibitor only cannot be explained by autophagy, and further investigation is required to explain this phenomenon. When 3-MA was added to the Jurkat cell group treated with chemotherapy drugs, the decrease in survival rate was associated with an increasing rate of apoptosis. This result is similar to the results of the study on Jurkat cells by Liu et al (16), which indicated that inhibiting autophagy could improve the chemotherapy effect on leukemia cells. According to these results, the different role of caspase-10 in HL-60 and Jurkat cells may be associated with the various biological characteristics of HL-60 and Jurkat cells. Lamy et al (14) showed that caspase-10 does not play the same role in lymphoma cells as it does in myeloma cells, and that the biological characteristics of Jurkat cells are more similar to lymphatic cells. This may be the reason for the different results in HL-60 and Jurkat cells.

As the present study has only preliminarily shown that caspase-10 could be associated with autophagy, the next stage of research would be to investigate the association between caspase-10 and autophagy in acute myeloid leukemia cells, and to determine the mechanisms or signaling channels for the caspase-10-associated regulation of autophagy in acute myeloid leukemia.

In conclusion, the role of caspase-10 may be associated with the basal levels of autophagy in acute myeloid leukemia cells, particularly when the cells meet stressful conditions, such as chemotherapy treatment. When caspase-10 is inhibited, ACD appeared in acute myeloid leukemia cells. However, there was no evidence to support a role for caspase-10 in autophagy in the acute lymphoid leukemia cells used in the present study. These results suggest a novel role for caspase-10 in the regulation of acute myeloid leukemia cell death and a novel method for the treatment of acute myeloid leukemia.

\section{Acknowledgements}

The authors would like to thank Mrs. Chen Hui and Mr. Yang Junjun for their skillful technical assistance, and Professor Zhu Xueqiong for funding assistance (all The Second Affiliated Hospital and Yuying Children's Hospital, Wenzhou, Zhejiang, China). The present study was supported by a program from the Wenzhou Science and Technology Bureau, Wenzhou, China (grant no. Y20140276).

\section{References}

1. Klionsky DJ, Cuervo AM, Dunn WA Jr, Levine B, van der Klei I and Seglen PO: How shall I eat thee? Autophagy 3: 413-416, 2007. 
2. Ma T, Zhu J, Chen X, Zha D, Singhal PC and Ding G: High glucose induces autophagy in podocytes. Exp Cell Res 319: 779-789, 2013

3. White E and DiPaola RS: The double-edged sword of autophagy modulation in cancer. Clin Cancer Res 15: 5308-5316, 2009.

4. Evangelisti C, Chiarini F, Lonetti A, Buontempo F, Neri LM, McCubrey JA, McCubrey JA and Martelli AM: Autophagy in acute leukemias: A double-edged sword with important therapeutic implications. Biochim Biophys Acta 1853: 14-26, 2015.

5. Nagelkerke A, Bussink J, Geurts-Moespot A, Sweep FC and Span PN: Therapeutic targeting of autophagy in cancer. Part II: Pharmacological modulation of treatment-induced autophagy. Semin Cancer Biol 31: 99-105, 2015.

6. Macintosh RL and Ryan KM: Autophagy in tumour cell death. Semin Cancer Biol 23: 344-351, 2013.

7. Pullarkat V, Meng Z, Donohue C, Yamamoto VN, Tomassetti S, Bhatia R, Krishnan A, Forman SJ and Synold TW: Iron chelators induce autophagic cell death in multiple myeloma cells. Leuk Res 388: 988-996, 2014

8. Ristic B, Bosnjak M, Arsikin K, Mircic A, Suzin-Zivkovic V, Bogdanovic A, Perovic V, Martinovic T, Kravic-Stevovic T, Bumbasirevic V, et al: Idarubicin induces mTOR-dependent cytotoxic autophagy in leukemic cells. Exp Cell Res 326: 90-102, 2014.

9. He W, Wang Q, Srinivasan B, Xu J, Padilla MT, Li Z, Wang X, Liu Y, Gou X, Shen HM, et al: A JNK-mediated autophagy pathway that triggers c-IAP degradation and necroptosis for anticancer chemotherapy. Oncogene 33: 3004-3013, 2014

10. Galluzzi L, Kepp O, Krautwald S, Kroemer G and Linkermann A Molecular mechanisms of regulated necrosis. Semin Cell Dev Biol 35: 24-32, 2014.

11. Lorin S, Hamai A, Mehrpour M and Codogno P: Autophagy regulation and its role in cancer. Semin Cancer Biol 23: 361-379, 2013.

12. Zhang SF, Wang XL, Yang XQ and Chen N: Autophagy-associated targeting pathways of natural products during cancer treatment. Asian Pac J Cancer Prev 15: 10557-10563, 2014.

13. Galluzzi L, Pietrocola F, Levine B and Kroemer G: Metabolic control of autophagy. Cell 159: 1263-1276, 2014

14. Lamy L, Ngo VN, Emre NC, Shaffer AL III, Yang Y, Tian E, Nair V, Kruhlak MJ, Zingone A, Landgren O and Staudt LM: Control of autophagic cell death by caspase-10 in multiple myeloma. Cancer Cell 23: 435-449, 2013.

15. Wilson NS, Dixit V and Ashkenazi A: Death receptor signal transducers: Nodes of coordination in immune signaling networks. Nat Immunol 10: 348-355, 2009.
16. Liu L, Yang M, Kang R, Wang Z, Zhao Y, Yu Y, Xie M, Yin X, Livesey KM, Lotze MT, et al: HMGB1-induced autophagy promotes chemotherapy resistance in leukemia cells. Leukemia 25: 23-31, 2011.

17. Zhang SP, Niu YN, Yuan N, Zhang AH, Chao D, Xu QP, Wang LJ, Zhang XG, Zhao WL, Zhao Y and Wang JR: Role of autophagy in acute myeloid leukemia therapy. Chin J Cancer 32: $130-135,2013$.

18. Watson AS, Mortensen M and Simon AK: Autophagy in the pathogenesis of myelodysplastic syndrome and acute myeloid leukemia. Cell Cycle 10: 1719-1725, 2011.

19. Mizushima N and Komatsu M: Autophagy: Renovation of cells and tissues. Cell 147: 728-741, 2011.

20. Kuma A, Hatano M, Matsui M, Yamamoto A, Nakaya H, Yoshimori T, Ohsumi Y, Tokuhisa T and Mizushima N: The role of autophagy during the early neonatal starvation period. Nature 432: 1032-1036, 2004.

21. Boya P, González-Polo RA, Casares N, Perfettini JL, Dessen P, Larochette N, Métivier D, Meley D, Souquere S, Yoshimori $\mathrm{T}$, et al: Inhibition of macroautophagy triggers apoptosis. Mol Cell Biol 25: 1025-1040, 2005.

22. Morselli E, Galluzzi L, Kepp O, Vicencio JM, Criollo A, Maiuri MC and Kroemer G: Anti- and pro-tumor functions of autophagy. Biochim Biophys Acta 1793: 1524-1532, 2009.

23. Degenhardt K, Mathew R, Beandoin B, Bray K, Anderson D, Chen G, Mukherjee C, Shi Y, Gélinas C, Fan Y, et al: Autophagy promotes tumor cell survival and restricts necrosis, inflammation, and tumorigenesis. Cancer Cell 10: 51-64, 2006.

24. Sato K, Tsuehihara K, Fujii S, Sugiyama M, Goya T, Atomi Y, Ueno T, Ochiai A and Esumi H: Autophagy is activated in colorectal cancer cells and contributes to the tolerance to nutrient deprivation. Cancer Res 67: 9677-9684, 2007.

25. Amaravadi RK, Yu D, Lum JJ, Bui T, Christophorou MA, Evan GI, Thomas-Tikhonenko A and Thompson CB: Autophagy inhibition enhances therapy-induced apoptosis in a Myc-induced model of lymphoma. J Clin Invest 117: 326-336, 2007.

26. Pel AA, Herr I, Schwarz H, Rodemann HP and Mayer A: Blocked autophagy sensitizes resistant carcinoma cells to radiation therapy. Cancer Res 68: 1485-1494, 2008.

27. Shimizu S, Kanaseki T, Mizushima N, Mizuta T, Arakawa-Kobayashi S, Thompson CB and Tsujimoto Y: Role of Bcl-2 family proteins in a non-apoptopic programmed cell death dependent on autophagy genes. Nat Cell Biol 6: 1221-1228, 2004. 